EPiC Series in Built Environment
Volume 1, 2020, Pages 161-169
Associated Schools of Construction Proceed-
ings of the 56th Annual International Conference

\title{
Case Study: Constructivist Learning Following an Interdisciplinary Studio for an NGO
}

\author{
Joseph P. Cleary, MS and Gregory F. Starzyk, JD, CPC \\ California Polytechnic State University \\ San Luis Obispo, CA
}

In the wake of a 2014 wildfire that destroyed 150 homes in Weed, CA, Great Northern Services, a non-governmental organization, reached out to Cal Poly with a constructivist-learning opportunity. In response, students were recruited into an interdisciplinary studio where teams competed to design work-force housing for a new subdivision. The winning design advanced to the detailed planning stage. A separate trio of construction management students designed their senior projects around producing shop drawings, procuring materials, organizing equipment, prefabricating the winning design's exterior walls and shipping them to the site. This case study documents the process and the lessons learned. In the end, two indicators of experiential learning, eight indicators of discovery learning, one indicator of problem-based learning, and one indicator of spiral learning were documented. Future research initiatives could quantify the efficacy of each constructivist variant; disaggregate these learning opportunities into smaller constructs with the potential to reach more students; and contemplate means of incorporating those potentials into either traditional classes or into integrated labs.

Key Words: Learn-by-Doing, Experiential Learning, Discovery-Learning, Problem-Based Learning, Spiral-Learning

\section{Introduction}

In the wake of a 2014 wildfire that destroyed 150 homes, Great Northern Services (GNS), a nonprofit non-governmental organization (NGO), reached out to California Polytechnic State University at San Luis Obispo, CA (Cal Poly). Cal Poly had facilitated resiliency planning and GNS now sought their help to design a small residential subdivision. Their goal was to build workforce housing and offer it for sale to local residents. By doing that, GNS hoped to jumpstart redevelopment in the community. Responding to their needs, a trio of faculty organized an interdisciplinary studio and challenged architecture, engineering and construction management students to design resilient workforce housing. The students were formed into teams that competed to create a unique housing design that met the criteria defined by GNS. To achieve cost-effectiveness, each team incorporated offsite fabrication or modularization into their design. In the end, a design that included panelized exterior walls was chosen. The faculty worked with an engineering consultant and general contractor 
who were engaged by GNS to approve detailed plans and apply for building permits. While the general contractor was placing the first foundation, a trio of construction management students began a senior project to draw spool sheets of each partition, procure materials for construction and organize equipment for fabricating the partitions. Aided by two faculty advisors and many student volunteers they then fabricated the exterior walls in a shop space on the university campus. When completed, these fabricated partitions were hoisted into an open-top shipping container and shipped to the site for erection. This case study documents the process and conveys the lessons learned.

\section{Literature Review}

The core academic subjects of construction management education are scheduling, estimating, methods and materials. Lessons are usually delivered in individual classes utilizing a lecture format (Chinowskly, Brown, Szajnman, \& Realph, 2006). But while the core courses are important, the knowledge conveyed in the core courses is insufficient to optimally perform construction operations. Managerial, industry, business, professionalism, legal, contractual, technical, and people skills are required (Ahmed, Yaris, Farooqui, \& Saqid, 2014). There are many ways to gain these skills in higher education. "The traditional segmented, topic-based approach to construction management curricula clearly has been successful at facilitating the attainment of specialized skills and concepts such as quantity surveying, estimating, or scheduling. However, the world does not always present problems that are topic specific and solved in a non-holistic manner" (Montoya, Kelting, and Hauck, 2009, p.66).

Learn by doing, hands on learning, experiential learning, active learning, service learning, projectbased learning, and problem-based learning are variants on the schema of experience, observe, and reflect learning methodology, also called the theory of constructivism (Greenwood, Janke, Donegan and Schwab, 2017). This theory suggests that people are active learners building knowledge upon experiences and improving that knowledge through social interaction or groups (Frank, Lavy and Elata, 2003). Constructivist variants can in many instances be used interchangeably.

Learn by doing, understood as the teaching of the head and the hand, alludes to knowledge and skills acquisition through two processes, experiential learning and discovery learning. Experiential learning arises from self-reflective observations that accompany progressive iterations of hands-on-learning. Discovery learning arises from facilitative reflections that motivates students to discover new information by deduction and construction. Greenwood, et al. explain that learn by doing “.... is an immersive, collaborative, process-oriented approach to the construction of knowledge and meaningmaking that results in career-ready students prepared and committed to apply whole-system thinking to solve local and global problems" (2017, p. xvi).

Problem-based learning (PBL) is an alternative to traditional learning environments involving primarily lecture delivery (Yildririm, Baur, LaBoube, 2014). PBL features hands on learning with the goal of longer retention of the desired learning outcomes. PBL activities can demonstrate increased performance compared to a traditional classroom setting. Barlow states that soft skills typically not learned through passive learning are developed and honed through PBL (2017).

Spiral learning (SL) adds to the value of PBL by introducing concepts at various points. Veladat \& Mohammadi list the goals of spiral learning as: "conceptualization, creativity, teamwork, individual work, to declare thoughts and achieve a hypothesis, to acquaint with terms, to apply images, knowledge, to interpret and criticize, learning , connect unfamiliar concepts with familiar ones, feeling trust, to extend information and the capability to maintain, pre-organizer, scientific thoughts" 
(2011, pp. 1118 - 1120). Construction educators are tasked with developing students that can manage and lead an overall construction process, not just to excel at topic specific problems or isolated skills (Davis and Cline, 2009). The ideal way to teach these subjects and skills has evolved to PBL offering several pedagogical advantages for construction management students where successful teamwork is required in the industry (Gunderson \& Moore, 2008). As a consequence of combining PBL and SL student performance improved (Jamie, et al. 2016).

PBL can require more preparation time than lecturing often causing time related stress for instructors (Chinowsky, et al. 2006; Frank, et al. 2003). A further challenge of PBL is a lack of student knowledge prior to beginning the activity (Yildririm, Baur, LaBoube, 2014). Students in one PBL course often struggled to synthesize the individual subjects and skills from the topic specific courses into the integrated components of a complete construction related project (Benhart, Cabrel, Hummard, Metzinger, Morgan \& Stanton, 2017). PBL often requires students to work in groups. Students working in a group can experience challenges such as: members dominating; members not contributing; pressure to accept differing ideas; and forceful conclusions (Gunderson \& Moore, 2008). Some students struggle to solve vague, complex, real-world problems as they transition into industry. However, integrating these PBL classes across the curriculum gives students additional opportunities to solve these problems and reinforce the competencies required at graduation and on the job (Benhart, et al. 2017).

Students exhibit a preference for the way they learn and receive information (Kumar, Kumar, Smart, 2004). Frank, et al. found that students prefer passive learning that requires less effort on their part and are not familiar with an active learning environment such as PBL (2003). However, Rokooei and Ford found that students and professionals perceive a studio-based curriculum as appropriate for construction management education (2019). Farrow, Liu, \& Tatum found that students prefer learning activities that include experienced instructors, outside service projects, visualization, pictures and videos, field trips, discussions, student and group teaching (2011). Further, a recent study by Kolgraff, Kline and Kelting found that on a forced rank survey of fourteen different instructional delivery methods students preferred and perceived that the top three most effective methods were hands-on building, working in a team, and in-class activities and discussion (2019). Through PBL and SL learning environments students feel that they learn and understand more (Gunderson \& More, 2008). They also feel an advantage working with unknown individuals that are outside of their comfort zone (Gunderson \& More, 2008). When real-world experiences were the project content in PBL, students were motivated to learn and work together more effectively towards their desired outcomes (Frank et al. 2003; Jaime et al. 2016; Maghiair, Sturges, Maurer, \& Jackson, 2015).

\section{Methodology}

\section{Program Curriculum}

The curriculum of the construction management program at Cal Poly is integrated. The program defines this integrated curriculum as a method of combining all of the core academic subjects such as scheduling estimating, materials and methods into a single course under an overarching theme, such as residential construction, commercial construction, or civil construction. The program is accredited by the American Council for Construction Education (ACCE). ACCE accreditation is maintained by demonstrating continuous improvement within a suite of performance standards and outcomes assessments. The university offers a comprehensive education, requiring a minimum of 72 quarterunits of general education for all baccalaureate degrees. Construction management majors must take seven practice-specific integrated lab courses. These labs cover fundamentals, residential, 
commercial, specialties, heavy civil, jobsite, and program management. Each of the integrated labs includes technical foundational information, estimating, scheduling, methods, material and a PBL component. Taken in sequence, these courses form an SL framework. Students in the program must also complete a senior project prior to graduation. This project is typically identified early in the 4th year, completed in that year, and presented during the evaluation period at the end of that year as the culminating experience of students' education.

\section{Background}

In 2014, the small northern California town of Weed was largely destroyed in a wildfire known as the Bowles Incident. GNS is an NGO whose mission is to "invigorate communities by initiating positive social change to improve economic conditions." GNS is promoting and financing the design and construction of a residential cluster on a site that they have purchased in Weed. The residences that they build on that site will be sold to low-and-moderate income families. Their aspirational goal for this activity is to incubate the further renewal of the town.

Seeking Cal Poly's participation, GNS had approached the Construction Management Department with their plans. They solicited for interest among faculty. A trio of faculty from architecture, engineering and construction management took an interest in their plan. GNS accepted the trio's proposal to organize an interdisciplinary studio in which student would design the housing. A local engineering firm and general contractor partnered with GNS to produce permit-ready plans, apply for permits and construct the housing. Students at a local community college proposed to organize a trades class that would, among other benefits, provide labor for construction.

The site is 1.3 acres, excluding the street, and zoned R4. It was subdivided into seven lots, each of which is designated for a single-family residence or duplex. Each house has approximately 1,200 sq. $\mathrm{ft}$. of gross floor space configured into 3 bedroom and 2 baths plus a garage. The site is sloped and the residences will be built on raised foundations with stem walls to accommodate the grade.

\section{Planning and Logistics}

In the 2019 winter quarter the senior project students developed a wall panelization plan from the permitted home construction drawings. They created a spool drawing for each panel (Figure 1). Quantity take-offs were performed from which material and hardware piece lists were created. A material cost estimate was developed from the quantity take-off. Local supplier pricing was solicited by the students and present to GNS for approval. A construction schedule, shop and project site logistics plans and a safety plan were developed for the work. Coordination of the work was arranged with campus facilities, the construction management department, and the individual faculty that would also be completing activities in the same space. Fabrication of the exterior wall panels took place in the 2019 spring quarter.

\section{Panel Construction}

Panel fabrication began in the second week of the 2019 spring quarter. The first step was to build a stage on the floor of the Simpson Strong Tie Lab (Figure 2). The stage allowed the wall studs to be constructed in plane and squared while the sheathing was fastened. Following completion of the stage, assembly of the wall panels began. The students tracked their productivity in number of panels per day and compared to the man-hours expended each day. They also tracked material consumption compared to the estimate from the spool drawings. One or two Simpson hoist clips, special purpose 
engineered connectors, were affixed to the top plate of each panel to assure safe rigging connections. As panels were completed, they were bumped onto dollies (Figure 2), wheeled out into a courtyard and staged in preparation for shipping (Figure 3). Once all the panels had been framed, sheathed, and stacked, a 40' open-top shipping container was delivered to the campus and placed as near the staging area as obstacles would allow. The students arranged for an appropriately sized boom truck to hoist the panels into the container. After received a quick refresher lesson on rigging and hand signals, and reviewing their safety plan, they loaded the panels for shipment (Figure 3).

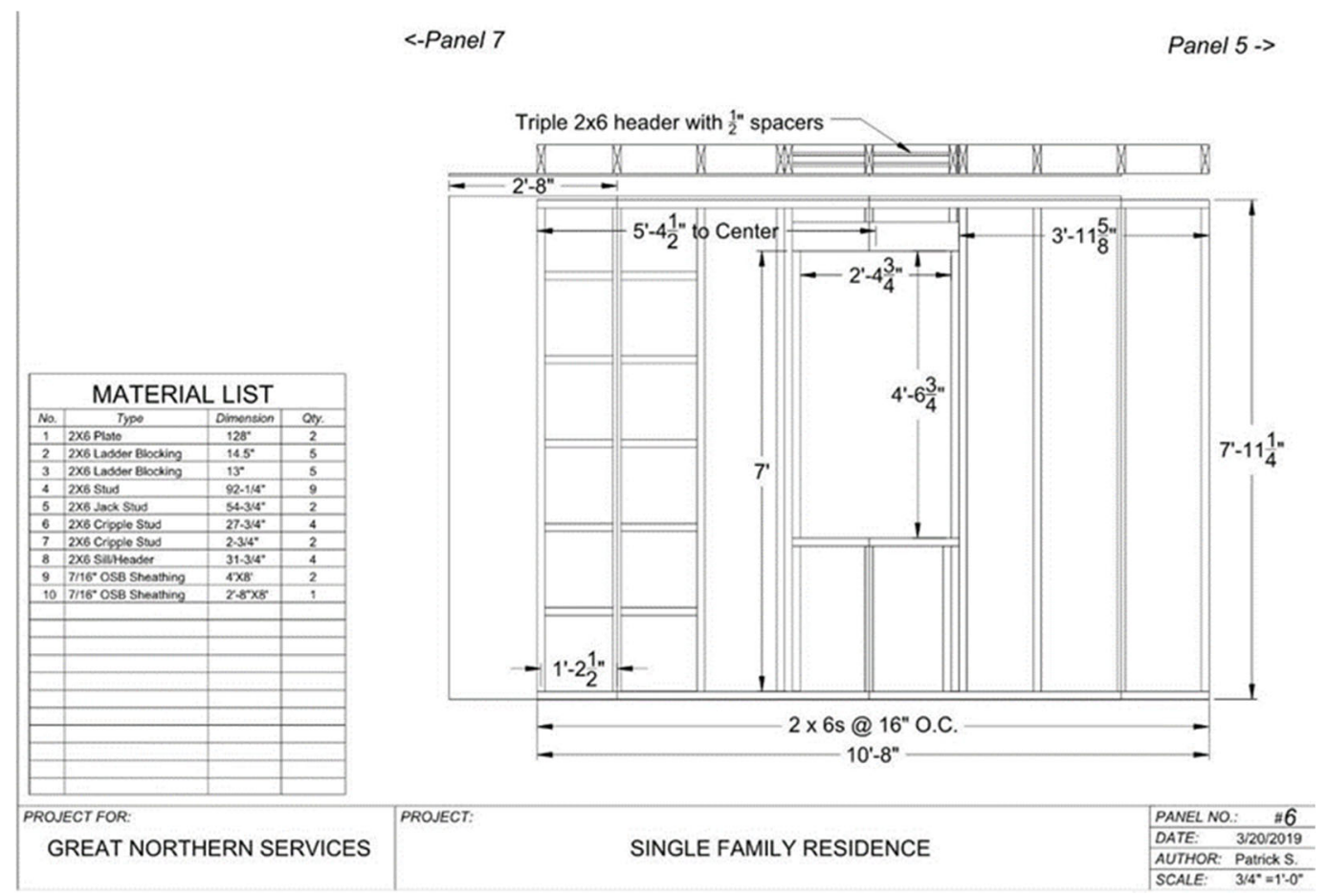

Figure 1. Panel drawing and material list

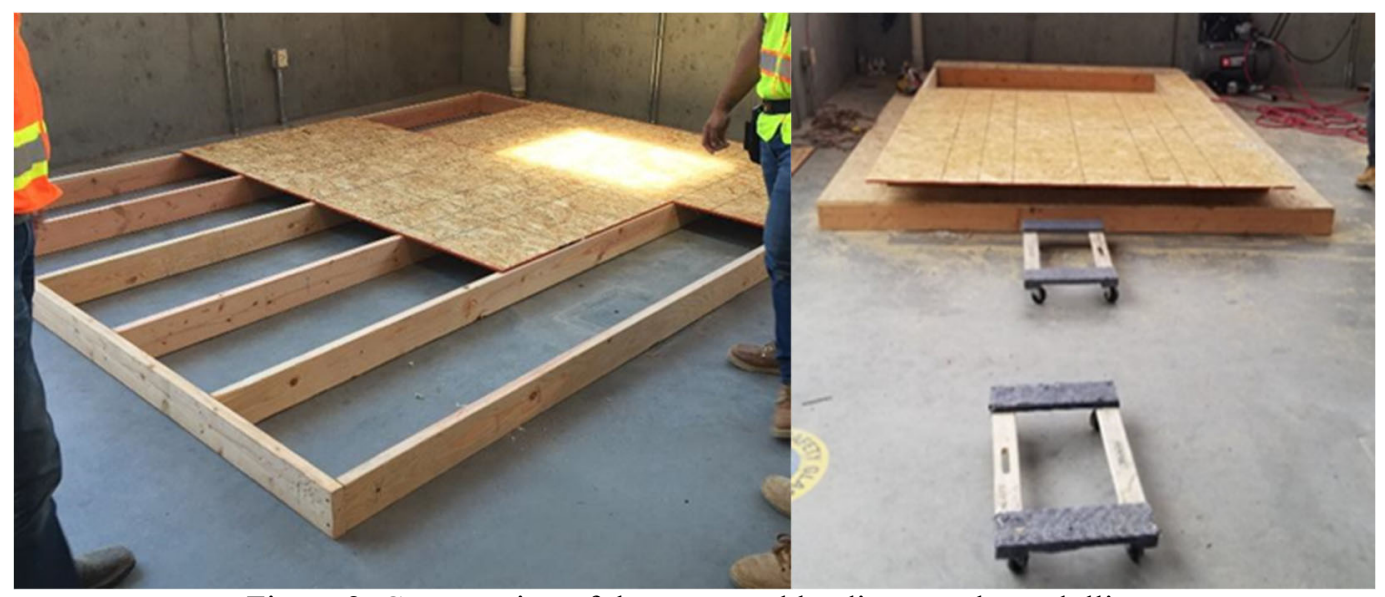

Figure 2. Construction of the stage and loading panels on dollies 


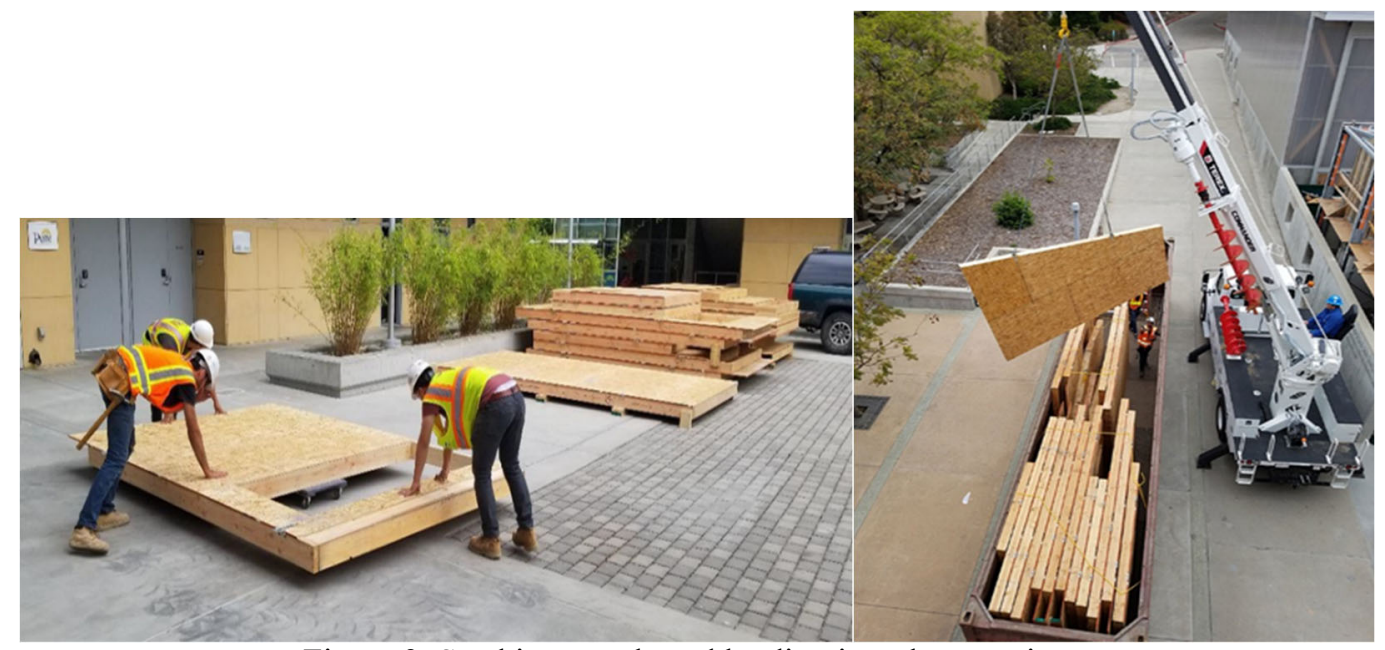

Figure 3. Stacking panels and loading into the container

\section{Student Responses}

After completion of their senior project the students were asked to provide their personal reflection on the panel production project. Below are their unedited responses.

\section{Construction Management Student 1}

"While building the panels was an enjoyable experience, it was certainly not an easy one. The work was physically demanding even when it was being done in the most favorable conditions. We were working inside a fabrication shop, protected from the sun, and the weather was fair each day. To think that carpenters perform this work in conditions very opposite to this has given me a deep and sincere appreciation for those working in the trades. I anticipate this appreciation will prove to be valuable, as my career will involve managing tradespeople who perform such demanding work. It will heavily influence the way I communicate and cooperate with these individuals, and the way I carry myself around them."

\section{Construction Management Student 2}

"The prefabrication of these exterior walls for Great Northern Services was an exciting opportunity for me. I definitely learned so much from doing quantity take offs, safety plans, logistic plans, building the panels, using Revit, using excel, communicating, and a lot of problem solving. This senior project showed me that construction is a team effort and you cannot do this process by yourself. Senior projects like this will definitely emphasize things you learned in classes. Some classes that I took away lessons from and applied it in this project were residential construction, commercial construction, jobsite, and BIM. Some key takeaways from the project are: respect the trades people because they really are talented and hardworking people, planning is very important in any project you take on in the future, find the best way to stay efficient and within budget, have alternative plans in case of your other plans do not work out, and lastly is listen and learn from more experienced professionals." 


\section{Construction Management Student 3}

"During the process of this project, the team had many conversations about the expected lessons that would come from the work we were doing. It would have been impossible to anticipate how much we would learn from this project. Trying to implement the lessons we had learned in the various classes we had taken proved to be a challenge. Many of us could not remember the specific lessons from our classes and had to be retaught a lot of the construction techniques. The most important lesson learned, applicable to far more than construction, was to have plan B, C, and D ready for when things take a turn. Thankfully this wasn't a huge problem for the GNS project until the final stages. Unfortunately, when it did become a problem, it had a large impact on our schedule and caused delays. The second important lesson learned is that there is no replacement for time and experience in industry."

"Regardless of the experience any of the students had from other carpentry projects in the past, or from the hands-on lab classes at the university, the professors worked more productively than all three of us students. Years in the industry had taught them how to work accurately and quickly. As time progressed, the students worked faster and with less error, but it was clear that years in industry had taught our supervisors how to cut their work time into a fraction of that of an amateur carpenter. There were also many tricks of the trade that were passed down from the supervisors to help quicken the process, or eliminate a step that was prone to errors. Some of these tricks became our project standards and would then be passed along to any volunteers. The final lesson taken away from this project is that more hands-on deck does not always mean more productivity. In fact, we quickly found our point of diminishing returns when we noticed volunteers standing around, or multiple people doing a job that only needed one person. Overall this project went very smoothly, and serves as a great baseline for future interdisciplinary project-based projects on campus."

\section{Discussion}

While the students don't participate in a formal cohort, moving through the construction management major sequence at the same time they had each received very similar preparation at the outset of this project based learning senior project. With all three students from the same discipline and with similar preparation, all similarly expressed outcomes in their reflections of an appreciation for the experience of professionals working in the trades and all three credited their experience with contributing future success planning projects.

Variants of constructivist learning were revealed in the personal reflections of the students: Two indicators of experiential learning were documented: 1) working alongside professionals is its own learning experience; and 2) what one learns in class has to be relearned in the field. Eight indicators of discovery learning were documented: 1) construction work is physically demanding; 2) empathy, communication, cooperation and one's demeanor with tradespeople is important; 3) planning is necessary for successful execution; 4) have a backup plan and a backup to the backup plan; 5) there is no substitute for time and experience in the industry; 6) the experienced worker is more productive, more accurate, and quicker; 7) tricks-of-the-trade can be passed down to improve the performance of inexperienced workers; and 8) more workers do not equate with higher productivity. One indicator of problem-based learning was documented: detailed work on a real problem enriched the student's understanding of core competencies; and one indicator of spiral learning was documented: individual learning yields to mastery through teamwork. 


\section{Conclusion}

In the end, a plethora of constructivist learning opportunities were documented from the senior projects upon which this case study was formed. One cannot help but to conclude that this was an extraordinarily rich learning environment. Yet the learning was obtained by just three students. Faculty engaging in this type of constructivist learning most certainly face challenges in adoption, such a training, preparation and resourcing. To build anything, students who are not carpenters, must first be trained in carpentry. Training in carpentry is done by other carpenters, ideally journeymen carpenters. But most faculty are neither journeymen carpenters nor can they become one quickly. Preparation includes identifying a client. A suitable client has a project that is designed, permitted and financed - a "shovel-ready" project. Resourcing involves purchasing or donation of materials; recruiting trainers; adequate shop space, tools and equipment; risk management and indemnification. Resourcing needs unmet can become insurmountable obstacles to faculty who wish to engage in this. Future research initiatives could quantify the efficacy of each constructivist variant; disaggregate these learning opportunities into smaller constructs with the potential to reach more students; and contemplate means of incorporating those potentials into either traditional classes or into integrated labs.

\section{References}

Ahmed, S. M., Yaris, C., Farooqui, R., \& Saqib, M. (2014). Key attributes and skills for curriculum improvement for undergraduate construction management programs. International Journal of Construction Education and Research, 10 (February 2015), 240-254.

Barlow, P. L. (2011). Development and delivery of an integrated project-based jobsite management undergraduate course. 47th ASC Annual International Conference Proceedings, 7(August), 3-21.

Benhart, B., Cabral, J., Hubbard, B., Metzinger, J., Morgan, P, and Santon, S. (2017). Construction Management Curriculum Transformation through Project-Based Learning; Part 1 of a Progressive Case Study. Associated Schools of Construction International Proceedings of the 53rd Annual Conference, 19-27.

Chinowsky, P. S., Brown, H., Szajnman, A., \& Realph, A. (2006). Developing knowledge landscapes through project-based learning, Journal of Professional Issues in Engineering Education and Practice, 132(April), 118-124.

Davis, K., and Cline, R. (2009). Improving Course Comprehension through Experiential Learning. Construction Research Congress 2009: Building a Sustainable Future, 339, 1409-1418.

Farrow, C., Ben, Liu, J., \& Tatum, M. C. (2011). Curriculum delivery and assessment for net generation construction students. International Journal of Construction Education and Research, 7(November), 109-125.

Frank, M., Lavy, I., \& Elata, D. (2003). Implementing the project-based learning approach in an academic engineering course. International Journal of Technology and Design Education, 13(3), 273-288.

Greenwood, P.B., Janke, D., Donegan, L., and Schwab, K. (2017) More than a motto: The Meaning Behind Cal Poly's Learn by Doing Signature, California Polytechnic State University 
Gunderson, D. E., \& Moore, J. D. (2008). Group learning pedagogy and group selection. International Journal of Construction Education and Research, 4(June 2013), 34-45.

Jaime, A., Blanco, J. M., Domínguez, C., Sánchez, A., Heras, J., \& Usandizaga, I. (2016). Spiral and project-based learning with peer assessment in a computer science project management course. Journal of Science Education \& Technology, 25(3), 439-449.

Keeley, J. W., English, T., Irons, J., \& Henslee, A. M. (2013). Investigating halo and ceiling effects in student evaluations of instruction. Educational and Psychological Measurement, 73(3), 440-457.

Kelting, S. (2011). Students' Perspectives about a Delivery System for a Residential Construction Management Course. Associated Schools of Construction International Proceedings of the 47th Annual Conference.

Kelting, S. and Hauck, A. (2010). Project-based delivery system for an integrated residential construction course. Associated Schools of Construction International Proceedings of the 46th Annual Conference.

Kelting, S., \& Holt, E.A. (2012). The Development of an Integrated Residential Construction Management Course. American Society for Engineering Education Proceedings of the 2012 Annual Conference.

Kumar, P., Kumar, A., and Smart, K. (2004). Assessing the Impact of Instructional Methods and Information Technology on Student Learning Styles. Issues in Informing Science and Information Technology, 1, 0533 - 0544.

Kolegraff, S., Kline, A., Kelting, S., (2019) Hands-On Building as an Instructional Delivery Method in an Integrated Lab Curriculum. Associated Schools of Construction International proceedings of the 55th Annual Conference, 33-40.

Maghiar, M., Sturges, D., Maurer, T., \& Jackson, M. (2015). Exploration of student perceptions, behaviors and academic performance in construction management classes. International Journal of Construction Education and Research, 11(4), 241-256.

Montoya, M., Kelting, S., and Hauck, A. (2009). Pilot Study of an Integrated Construction Management Curriculum. Associated Schools of Construction International Proceedings of the 45th Annual Conference, 59 - 66.

Rokooei, S., \& Ford, G. (2019). Comparison of industry and students' perceptions in a studio-based construction program. Associated Schools of Construction International Proceedings of the 55th Annual Conference.

Veladat, F., \& Mohammadi, F. (2011). Spiral learning teaching method: Stair stepped to promote learning. Procedia - Social and Behavioral Sciences, 29(Iceepsy), 1115-1122.

Von Kotze, A., \& Cooper, L. (2000). Exploring the transformative potential of project-based learning in university adult education. Studies in the Education of Adults, 32(2), 212. 